\title{
Addressing the family planning needs of HIV-positive PMTCT clients: Baseline findings from an operations research study
}

Carolyn Baek

Naomi Rutenberg

Population Council

Follow this and additional works at: https://knowledgecommons.popcouncil.org/departments_sbsr-hiv How does access to this work benefit you? Let us know!

\section{Recommended Citation}

Baek, Carolyn and Naomi Rutenberg. 2005. "Addressing the family planning needs of HIV-positive PMTCT clients: Baseline findings from an operations research study," Horizons Research Update. Washington, DC: Population Council. 


\section{Hgrizons}

\section{Addressing the Family Planning Needs of HIV-POSITIVE PMTCT CLIENTS: Baseline Findings from an Operations Research Study}

Preventing unintended pregnancy among HIV-positive women is an effective approach to reducing pediatric HIV infection and vital to meeting HIV-positive women's sexual and reproductive health needs (WHO 2002, 2004; UNFPA 2004). Although contraceptive services for $\mathrm{HIV}$-positive women is one of the four cornerstones of a comprehensive program for prevention of mother-to-child transmission of HIV (PMTCT), ${ }^{1}$ a review of PMTCT programs found that implementers have not prioritized family planning (Rutenberg and Baek 2004). While there is increasing awareness about the importance of family planning and HIV integration, data about family planning from PMTCT clients are lacking.

The Horizons Program, in collaboration with International Medical Corps (IMC) and Steadman Research Services International (SRSI), is conducting an operations research study testing several community-based strategies to reduce mother-to-child transmission of HIV in a densely settled urban slum area in Nairobi, Kenya. The strategies being piloted by IMC include moving PMTCT services closer to the population via a mobile clinic, and increasing psychosocial support for HIV-positive women through the use of traditional birth attendants and peer counselors. Peer counselors are HIV-positive women who have already received PMTCT services. The effectiveness of each of these strategies on women's utilization of key PMTCT services, including family planning, will be measured by comparing baseline to follow-up data.

This research update presents key findings about family planning at PMTCT sites, including the interaction between providers and clients as well as HIV-positive women's fertility desires and demand for contraceptives, from the baseline cross-sectional survey and qualitative interviews with postpartum women.

\section{Methods}

A total of 1,803 women with infants aged 10 weeks or younger took part in exit interviews at six high volume primary health clinics in Kibera and Dagoretti, two urban slums in Nairobi, Kenya. These structured interviews, which covered family planning and other PMTCT topics, were conducted in Kiswahili and were carried out from June to August 2004.

In October and November 2004, the researchers conducted in-depth interviews to further explore issues raised in the quantitative survey. The purposeful sample included $24 \mathrm{HIV}$-positive women and $5 \mathrm{HIV}$-negative women with infants aged 10 weeks or younger. Interviews were conducted in Kiswahili, recorded, transcribed, and then translated into English. The qualitative data in this update are based on the interviews with the HIV-positive women. 


\section{Profile of the Sample}

Among the 1,803 women interviewed, 60 reported that they were HIV-positive and 1,175 stated that they were HIV-negative. A substantial number of women $(n=568)$ either would not indicate their status to the interviewer or did not know their status despite testing either because they did not pick up their result or because they never underwent HIV testing. For ease of reference, these women will be referred to as 'unknown' HIV status. Given that service statistics from these clinics show an HIV prevalence rate of about 14 percent, it is likely that respondents under reported their true status

Overall, the women share similarities in their sociodemographic profile. On average, the women interviewed were in their mid-20s, with an average of 2.1 to 2.6 children, and were just over a month postpartum. Nearly three-fourths of those who learned their status and chose to disclose it to the interviewer had completed at least 8 years of schooling, while over half of women with unknown status did so. There were two areas of statistically significant differences among those who disclosed their status. A greater percentage of HIV-negative women were married or cohabiting compared to HIV-positive women ( $<$.05). A greater percentage of HIV-positive women reported that they were widows, suggesting that the spouse may have already passed away due to AIDS-related illness. Moreover, HIV-positive women were more likely to have an income than HIV-negative women

$(\mathrm{p}<.05) .($ See Table 1$)$

Table 1 Sociodemographic data by HIV status

$\begin{array}{cc}\text { Mean } & \text { Married or } \\ \text { age } & \text { cohabiting }\end{array}$

(\%)

$\begin{array}{cc}\begin{array}{c}\text { Mean } \\ \text { number }\end{array} & \begin{array}{c}\text { Completed } \\ \text { primary } \\ \text { of living } \\ \text { children }\end{array} \\ \begin{array}{c}\text { education } \\ \text { (8 years) } \\ \text { or higher (\%) }\end{array}\end{array}$

2.6

2.1

2.2
72

54

\begin{tabular}{llllll}
\hline HIV $+(n=60)$ & 26.3 & $72^{*}$ & 2.6 & 73 & $52^{*}$ \\
HIV $-(n=1,175)$ & 24.4 & $86^{*}$ & 2.1 & 72 & $33^{*}$ \\
Unknown $(n=568)$ & 23.8 & 77 & 2.2 & 54 & 31
\end{tabular}

Woman has

some amount

of income

(\%)

*Statistically significant in 2-way comparison between HIV-positive and HIV-negative women.

Among the $24 \mathrm{HIV}$-positive women who participated in the in-depth interviews, 14 were married or cohabitating. One was single, three were separated from their partner, and six were widows. These HIV-positive women were slightly older than women in the quantitative survey, averaging 28.1 years of age with a median of 26. They also had more living children, with a mean of 3.3 and a median of 3 .

\section{Key Findings}

\section{HIV-positive women are significantly more likely than HIV-negative women to say that they do not intend to have more children.}

Women were asked, "Do you intend to have another child within one year, within two to three years, after three years, or not at all." The overwhelming majority of HIV-positive women (82 percent) reported not intending to have another child. In marked contrast, just about a third of HIV-negative women and women of 
unknown status indicated as such $(\mathrm{p}<$.0001) (Figure 1). After controlling for the number of living children, $\mathrm{HIV}$-positive women were 7.5 times more likely to not want another child compared to their HIV-negative counterparts. Among the 18 percent of HIV-positive women who did want more children, this was mostly after 3 years, suggesting the desire for spacing between children.

\section{Figure 1 Percent of women not planning to have another child}

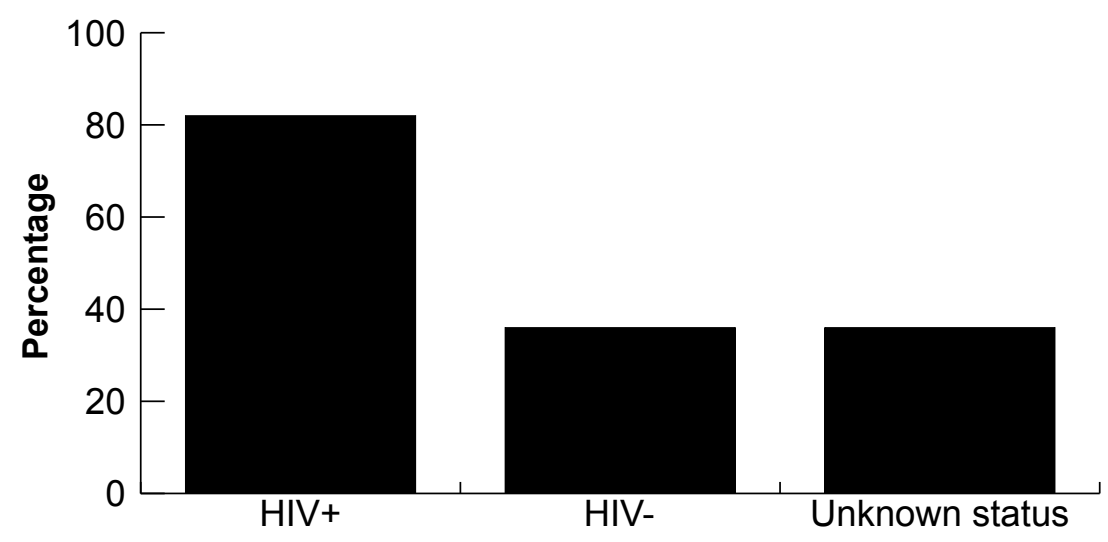

During the in-depth interviews women were asked whether they wanted to have more children and what effect, if any, HIV had on their desire to have or not to have more children. ${ }^{2}$ Twenty-two out of $24 \mathrm{HIV}$ positive women stated that they did not want to have more children. While all $24 \mathrm{HIV}$-positive women indicated that HIV adversely affected their desire to have further children, the ways in which their status affected fertility decisions varied. Many women demonstrated concern for their own health. Some translated being healthy as having a sufficient quantity of blood, and thus a future pregnancy was seen as detrimental given the loss of blood. More than half of the women $(n=13)$ expressed that they needed to take care of existing children, and some mentioned how it was already difficult to provide basic necessities for them. Eleven women overestimated the risk of vertical transmission; these individuals believed that an HIV-positive woman would definitely have an HIV-positive infant.

"I don't want more children because I am comfortable with the ones I have. With my HIV-positive status if I go on giving birth I will end up getting $H I V$-positive babies, which I don't want. When you are $H I V$-positive and pregnant you lose strength, have no appetite, you feel dizzy, fall sick often. You are stressed..."

29 year-old separated woman with three children

"At the moment I am not healthy to give birth to more children... For the time that I will be living I need to take care of my children. I have problems, I have no job and now that my husband has run away I might find people who will cheat me and I could get pregnant and I don't want to get more children. You know when you give birth you lose a lot of blood and when this blood is in my body I can use it to build my strength now that I have the virus."

25 year-old married woman with two children

But a 26 year-old widow with just one child displayed mixed feelings about future childbearing. That she has less than the average desired family size in her community (APHRC 2002) may play into her ambivalence. 
"I can get more children and I have to give them space before another one comes. Since I am positive I feel I can have one or two children and if God decides to take all of them or one I remain with one. So I feel it is important to have more children so that even if God takes one of them, you never know his plans... I am HIV-positive and this cannot allow me to have more children. If I do so my health continues to deteriorate."

\section{Many women had not discussed family planning with a provider during antenatal care.}

Fifty percent of HIV-positive women and 58 percent of HIV-negative women reported that a provider had not discussed family planning with them that day or at an earlier visit. Seventy-five percent of women with unknown status reported no discussion with a provider about family planning. While there may have been underreporting of family planning counseling in response to the survey question (see next section), these results suggest that family planning is not regularly addressed in antenatal care visits given that over 90 percent of women in the entire survey sample $(n=1,803)$ went to an antenatal care facility at least once during their pregnancy. While the vast majority of women had yet to return to sexual activity, a tenth of HIV-positive women and a quarter of HIV-negative women and those of unknown status had already resumed sexual relations.

\section{Providers give directive counseling for HIV-positive women that encourages family planning and discourages further children.}

In contrast to the quantitative sample of HIV-positive women ( $n=60)$, most HIV-positive women in the qualitative sample (21 out of 24) answered yes when asked if a health provider discussed family planning today or at an earlier visit. Twenty of the 21 women indicated receiving directive counseling. As reported by these women, the clear take home message was that family planning should be used. These women appeared to have been influenced by what the provider says regarding future childbearing; when explaining why they did not want more children, some women used similar language they reported receiving from providers. The main reason was to protect women's health given their serostatus.

"She told me that since I was HIV-positive I should not continue to give birth because my health will continue to deteriorate."

"That it was not good to have another baby while I was HIV-positive because when I give birth I lose a lot of blood and may not live for long. Instead I was advised to use a condom."

While more than half of the HIV-positive women who received counseling $(n=21)$ reported that providers recommended not having any more children in light of their serostatus, a couple of women remembered the provider also discussing birth spacing in the context of being HIV-positive.

"She told me that if I continue giving birth my health would deteriorate considering my status. She also told me to plan my family so that I can give time for my children to grow accordingly."

Several women recalled the provider discussing what to use for family planning, mentioning the importance of using condoms.

"She told me it was better if I used a condom for family planning so as not to infect others or get more viruses." 


\section{Postpartum family planning use is similar for HIV-positive and HIV-negative women.}

Among the women who were 6-10 weeks postpartum, 13 percent of HIV-positive women, 20 percent of HIV-negative women, and 15 percent of women of unknown status were using a modern contraceptive method. ${ }^{3}$

Questions about the use of specific methods demonstrate that there is no significant difference in use between HIV-positive and HIV-negative women (Table 2). Although the numbers are small, HIV-positive women are less likely to use hormonal injections than HIV-negative women. This may be due to HIV-positive women viewing normal bleeding as a tangible measure of their health as mentioned in the in-depth interviews. Irregular bleeding, which can be a side effect of injections, may make HIV-positive women hesitant to use this method.

Table 2 Family planning use at 6-10 weeks postpartum by HIV status (\%)

\begin{tabular}{lcccccccc}
\hline & Pill & $\begin{array}{l}\text { Hormonal } \\
\text { injections }\end{array}$ & Condom & IUD & Norplant & $\begin{array}{l}\text { Female } \\
\text { steril- } \\
\text { ization }\end{array}$ & $\begin{array}{l}\text { Natural } \\
\text { family } \\
\text { planning }\end{array}$ & Withdrawal \\
\hline $\begin{array}{l}\mathrm{HIV}+ \\
(\mathrm{n}=24)\end{array}$ & 4 & 0 & 8 & 0 & 0 & 0 & 0 & 0 \\
$\begin{array}{l}\mathrm{HIV}- \\
(\mathrm{n}=519)\end{array}$ & 3 & 11 & 4 & 1 & 0 & 1 & 4 & 1 \\
$\begin{array}{l}\text { Unknown } \\
(\mathrm{n}=212)\end{array}$ & 5 & 4 & 6 & 0 & 0 & 1 & 9 & 1
\end{tabular}

\section{Most HIV-positive and HIV-negative women intend to use contraceptives in the future and view several methods favorably.}

Most women planned to use some kind of contraceptive method in the future regardless of their HIV status, demonstrating broad demand for family planning. Women were also asked about their intention to use specific methods of contraception. As there was no timeframe given, interviewees responded yes to any and all methods they saw themselves possibly using. Disaggregated by serostatus, HIV-positive women are significantly less likely to intend to use hormonal injections $(\mathrm{p}<.01)$ or natural family planning $(\mathrm{p}<.05)$, and significantly more likely to use condoms $(\mathrm{p}<.01)$ than their HIV-negative counterparts (see Table 3$)$.

Data from the in-depth interviews support this finding about intention to use condoms because of their role in HIV prevention and/or as a contraceptive.

"When I was at the clinic the sister advised me to use a condom now that I was sick and we didn't know my husband's status."

"It's appropriate to use condoms so as not to get pregnant and give birth to HIV-positive children." 
Table 3 Intention to use family planning by HIV status (\%)

\begin{tabular}{|c|c|c|c|c|c|c|c|c|c|c|}
\hline & Pill & $\begin{array}{l}\text { Hormonal } \\
\text { injections }\end{array}$ & Condom & $\begin{array}{l}\text { Diaphragm, } \\
\text { foam, jelly }\end{array}$ & IUD & Norplant & $\begin{array}{l}\text { Female } \\
\text { steril- } \\
\text { ization }\end{array}$ & $\begin{array}{l}\text { Male } \\
\text { steril- } \\
\text { ization }\end{array}$ & $\begin{array}{l}\text { Natural } \\
\text { family } \\
\text { planning }\end{array}$ & $\begin{array}{l}\text { With- } \\
\text { drawal }\end{array}$ \\
\hline $\begin{array}{l}\text { HIV + } \\
(n=60)\end{array}$ & 32 & $35^{*}$ & $47^{*}$ & 2 & 3 & 12 & 15 & 5 & $10^{*}$ & 3 \\
\hline $\begin{array}{l}\text { HIV- } \\
(n=1,175)\end{array}$ & 27 & $69^{*}$ & $28^{*}$ & 1 & 6 & 20 & 18 & 6 & $26^{*}$ & 15 \\
\hline $\begin{array}{l}\text { Unknown } \\
(n=568)\end{array}$ & 26 & 61 & 21 & 2 & 7 & 12 & 12 & 5 & 16 & 6 \\
\hline
\end{tabular}

*Statistically significant in 2-way comparison between HIV-positive and -negative women.

\section{Multiple factors influence how HIV-positive women decide to use family planning.}

Similar to findings in the quantitative survey, the in-depth interviews revealed that most HIV-positive women (20 out of 24) expressed intention to use family planning. From these 20, there were a variety of responses regarding how a woman would decide to begin using family planning as well as how to decide which method to use. In terms of individuals involved in the decision-making process, the most common response was the provider, with eight women mentioning a provider. Women viewed providers as a helpful resource with whom they would consult, including getting advice about when to begin and/or what method to use. According to one woman, "My provider will tell me the method to use that will suit me." Several women said they themselves would decide. Only one woman indicated that she would decide with her husband.

In addition to who would be involved in the decision making, women commented on the factors that lead to a decision. Seven out of 20 women spoke about how they wanted to use family planning because they were HIV-positive or remarked about their deteriorated health. For example, one woman planned to start contraceptives closer to delivery than in the past: "I usually stay for a year after giving birth but because of my status I will start using the injection soon before a year is over." For another woman, upon receiving a positive test result, her plans about future childbearing changed. "When I found out that I was positive, I felt there was no need to get another child." Several women brought up timing, such as six weeks after delivery or the onset of their period, as the determining factor of when to start.

\section{Women identified side effects as a major reason not to use family planning.}

As a way to tap into community beliefs about family planning that may also reflect some of the women's own concerns, women were asked in the in-depth interviews why women in these communities may not use family planning even if they do not want to get pregnant. The responses to this question largely focused on the side effects of contraceptives, with about half of the women mentioning this. Not only was there a long list of minor side effects associated with family planning, some women attributed serious health issues with contraceptives.

"Ifyou family plan and you are positive you will not get your monthly periods and this will not make sicknesses come out of your body." 
Other themes that emerged to a lesser degree were religious reasons, ensuring a sufficient number of living children, and that men may not want women to use family planning.

\section{Although being HIV-positive inhibits partner communication, the vast majority of HIV-positive women felt they could talk about HIV and family planning.}

In the quantitative survey, 72 percent $(n=47)$ of HIV-positive women with a partner/husband indicated they could talk to them about HIV. However, HIV-negative women are significantly more likely to indicate that they could talk with a partner/husband about HIV, with 93 percent $(n=1,084)$ reporting as such $(\mathrm{p}<$.0001). These results underscore how HIV status can affect women's ability to talk with their husband/ partner about HIV. This may have implications for family planning decisions since disclosure of HIV status can be an important step to discussions as a couple about whether or not another child is desired, and about using family planning.

When asked how she felt about talking to her husband/partner about family planning, 10 out of the $15 \mathrm{HIV}$ positive women felt free to do so in the qualitative sample. The five others said they did not feel comfortable, expressing, for instance, that family planning needed to be a secret since he would not accept it or that she had not disclosed her HIV status to him.

Surveyed women were also asked about the possibility of talking with a partner/husband about condom use to prevent pregnancy. The results were similar regardless of serostatus: 72 percent of HIV-positive women and 75 percent of HIV-negative women felt comfortable or somewhat comfortable, underlining the overall acceptability of condoms as a family planning method.

\section{Conclusions and Program Recommendations}

These baseline data highlight that most HIV-positive women do not plan to have additional children. Yet these findings must be interpreted in the context of several characteristics of this setting. In this study, HIVpositive women who indicated that they did not want more children already had on average 2.8 children. More research is needed about demand for family planning among HIV-positive women who have no children or just one child.

Providers play a large role in influencing how women feel about future childbearing. These data demonstrate that providers have steered HIV-positive women away from future childbearing mainly due to concern about the woman's health given her serostatus. Moreover, the lack of accurate information given to clients about the possibility of vertical transmission may also deter women from wanting another child. HIV-positive women expressed various considerations that are involved in their desire not to have further children, such as their own health concerns, already having a sufficient number of children, not wanting to pass on the virus, and economic vulnerability.

In this setting, there is significant demand by HIV-positive women for family planning in general, and condoms in particular. Yet side effects are identified as the most important reason why women in these communities may not use contraceptives even if they do not want to become pregnant.

These results provide important information that can be used by program managers providing family planning counseling and services to HIV-positive women. Program recommendations are as follows: 
- Interventions should focus on providers since these data suggest that they have an instrumental role in affecting women's decision-making regarding family planning. Providers should be trained to support HIV-positive women in achieving their sexual and reproductive health goals.

- Side effects continue to be a major issue for these women. Peer approaches, e.g. satisfied users, may be effective in reassuring women about the safety of contraceptive methods.

- Women are concerned about their own health as well as their ability to take care of existing children. Programs should give care and support to women and their children by offering PMTCT+ services.

${ }^{1}$ The other three cornerstones are primary prevention of HIV infection in women, reducing transmission from $\mathrm{HIV}$-infected pregnant and lactating women to their children, and care and support of women, infants, and families infected and affected by HIV/AIDS.

${ }^{2}$ These in-depth interview questions were adapted from Kirshenbaum, Sheri B. et al. 2004. "Throwing the dice": Pregnancy decision-making among HIV-positive women in four U.S. cities. Perspectives on Sexual and Reproductive Health, 36(3):106-113.

${ }^{3}$ Among the subset of women who had resumed sexual activity, two out of two HIV-positive women, 38 percent $(n=209)$ of HIV-negative women, and 34 percent $(n=85)$ of women of unknown status were using a modern method of contraception.

April 2005

\section{References}

African Population and Health Research Center (APHRC). 2002. Population and Health Dynamics in Nairobi's Informal Settlements. Nairobi: African Population and Health Research Center.

Rutenberg, Naomi and Carolyn Baek. 2004. Review of field experiences: Integration of family planning and PMTCT services. Washington, DC: Population Council.

UNFPA. 2004. "The New York call to commitment: Linking HIV/AIDS and sexual and reproductive health." New York: UNFPA. Accessed from http://www.unfpa.org/icpd/10/docs/hiv_aids_rh_call_commitment.doc

WHO. 2002. "Strategic approaches to the prevention of HIV infection in infants: Report of a WHO meeting." Morges, Switzerland, 20-22 March. Geneva: WHO.

2004. "The Glion call to action on family planning and HIV/AIDS in women and children: 3-5 May 2004." Geneva: WHO. Accessed from http://www.who.int/reproductive-health/rtis/docs/glion_cal_to_action.pdf

The study team includes Peter McOdida, Benson Ulo, and Grace Muthumbi of International Medical Corps; Carol N'Katha-Matiko and Catherine Lidonde of Steadman Research Services International; and Carolyn Baek, Susan Kaai, Scott Geibel, and Naomi Rutenberg of Horizons/Population Council.

Suggested citation: Baek, Carolyn and Naomi Rutenberg. 2005. "Addressing the family planning needs of HIV-positive PMTCT clients: Baseline findings from an operations research study,” Horizons Research Update. Washington, D.C.: Population Council.

This document may be reproduced in whole or in part without permission of the Population Council provided full source citation is given and the reproduction is not for commercial purposes. by the Office of

HIV/AIDS, Bureau for

Global Health, U.S.

Agency for International

Development, under the

terms of HRN-A-00-97.

00012-00. The opinions

expressed herein are those

of the authors and do not

necessarily reflect the

views of the U.S. Agency

for International

Development.

For more information,

contact:

Population Councl//Horizons

Communications Unit

4301 Connecticut Ave, NW

Suite 280

Washington DC 20008

USA

Tel: $+202-237-9400$

Fux: + 202-237-8410

Email: horizons@pcdcorg

htup//wwwpopcouncil.org/ horizons/horizons.html

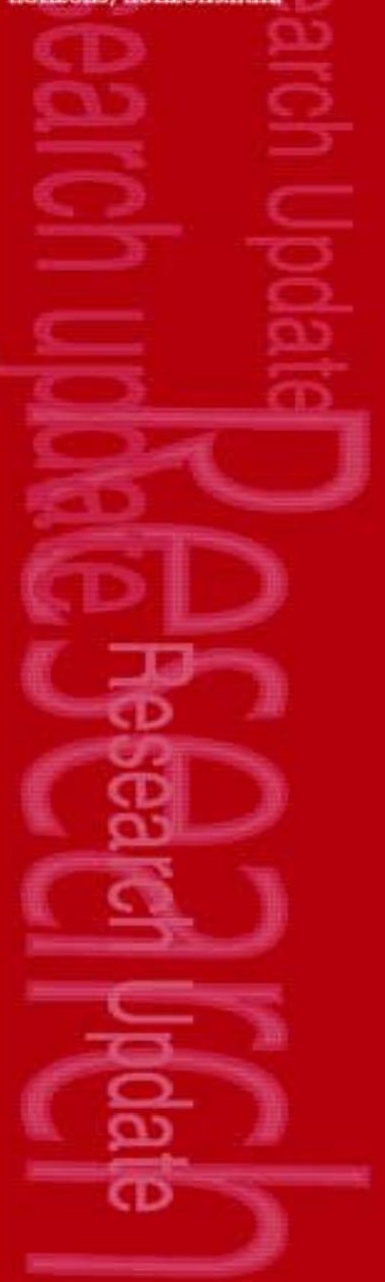

